\title{
Research on Function Differentiation of Three-dimensional Finance under the Perspective of High Quality Employment
}

\author{
Kong Weiwei $^{1, a}$, Yin Haoran ${ }^{1, b}$, and Qin Weixin ${ }^{2, c}$ \\ ${ }^{1}$ Harbin University of commerce, Harbin, China \\ ${ }^{2}$ Liaoning University, Shenyang, 110036, China \\ akww119@sina.com, ${ }^{\mathrm{a} k w w 119 @ s i n a . c o m,{ }^{c} k w w 119 @ s i n a . c o m ~}$
}

Keywords: high quality employment; 3D finance; financial function differentiation

\begin{abstract}
Employment is the first goal of macroeconomics policy of nations and vital to people's livelihood. High quality development is the ambition to the improvement of human society. On the basis of previous studies, we use principle of marginal effect to test the quality of employment and regard the marginal output and marginal return as the main line to analyze the high quality of employment. Firstly, it demonstrates that the overall low quality of employment in our country in the recent 20 years mainly reflected in the quality of rural employment is negative; Secondly, under the three dimensional financial perspective, it basically confirms that the key factors to the negative quality of rural employment are the opposite and functional differentiation influence on employment quality by policy finance, rural cooperative finance and commercial finance of the three-dimensional finance frame. Then, we analyze deep level reasons for differentiation effect and influence on employment quality by the 3D finance from the angel of theory and practice. Finally, we put forward the suggestions that the key to the high quality of employment are to re-examine the proposition of countryside surplus labor force shift and first return from differentiation to the unified function of 3D finance effectively.
\end{abstract}

\section{Literature review}

Employment is vital to people`s livelihood, and high quality employment is an important topic for the human beings to advance and develop. William Petty (1662) first proposed the basic principles of labor-time and value determined which points out that Labor is father of wealth. Adam Smith (1776) discussed labor wages in The Wealth of Nations, making a comparison between labor remuneration and the national wealth, saying that "Abundant remuneration is the inevitable result of the promotion of national wealth, also is the physical feature of country's wealth promotion". ${ }^{[1]}$ Marx (1848) first built the theory of labor dual, proposed that abstract labor create value, and value is determined by labor time. Ruddolf Hilferding (1910) talked about the struggle of labor contract in Financial Capital, pointing out that union fought over labor income. The higher the profit margin was, the more effectively the activities were carried out. In this way, the union militancy evolved into a political struggle, and enriched the union activities ${ }^{[2]}$. In the 1930s, after analyzing the input and output of manufacturing from1899 to 1922, Cobb and Douglas put forward the production functions, suggesting that capital and labor both can create value, contribution rate of labor is 0.75 , while capital $0.25^{[3]}$. Solomon (1956) pointed out that the average output of each worker was determined by the average wage and efficiency of labor (the improvement of technology). He also thought that in the process of balanced growth, the growth rate of output per worker was only determined by technical progress rate ${ }^{[4]}$. Dong Ke (2005) thought that the imperfection of financial system in Japan caused the long-term slow growth, leading to the rising unemployment rate ${ }^{[5]}$. Hamid Boustanifar (2014) believed that during the process of manufacture, labor include variable and fixed cost. Similar to cost, the labor needs financial support, and even in the case of constant investment, credit market with efficiency will improve the level of employment. ${ }^{[6]}$ 


\section{Test of employment quality based on marginal effct}

According to Cobb-Douglas production functions, we select the number of employment in urban and rural areas from1995 to 2013 as the independent variables (L), and the corresponding GDP growth rate as the dependent variables $(\mathrm{Y})$ and other influence factors as random disturbance term. Then, the preliminary model is as follows.

$$
\mathrm{Y}_{\mathrm{t}}=\alpha+\beta_{1} \text { Lcity }_{\mathrm{t}}+\beta_{2} \text { Lrural }_{\mathrm{t}}+\xi_{\mathrm{t}} \text {. }
$$

Among them, $\alpha$ is the constant term, $\xi_{\mathrm{t}}$ is the random error term.

The data comes from China Statistical Yearbook. In order to keep the stability of data, we use the software SPSS20.0 to calculate the natural logarithm of the data. After the assessment, we can get the results as follows.

$$
\begin{aligned}
& Y_{\mathrm{t}}=\mathrm{e}^{16.155 * \text { Lcity }_{\mathrm{t}}}{ }^{2.382 *} \text { Lrural }_{\mathrm{t}}{ }^{-2.649} \\
& \text { (3.525) (20.240) }
\end{aligned}
$$

$\mathrm{R}^{2}=0.999$, Adjusted $\mathrm{R}^{2}=0.997, \mathrm{~F}=3572.060$, the three variables above all undergo the test of significance at a rate of $1 \%$.

As for the $2^{\text {nd }}$ model, we get the natural logarithm of each term of the equation, and take the derivative of $t$, then, we get the following equation:

$$
\mathrm{g}_{\mathrm{y}}=2.382 * \mathrm{~g}_{\mathrm{c}}-2.649 * \mathrm{~g}_{\mathrm{r}}
$$

From the assessment model (2) and (2) ${ }^{*}$, we can see that, the growth of employment in rural area have an effect on the growth of economy at a rate of 2.382, while this rate in urban is -2.649. From the view of employment growth effect on economy growth, when there is two more person have been employed in a rural and a urban area separately, the influence of employment growth on the whole economic is -0.267 . That is to say, the employment in rural and urban both rise at 1 percent, the actual economic on the whole goes down at a rate of $0.267 \%{ }^{(1)}$. Only in this way can the marginal output turn negative into positive. At the same time, the judgment is corresponding with the facts that the employment population is falling down by $20 \%$ and compound growth rate by $1.16 \%$ in the past 20 years. It is obvious that the employment quality in our country is low from the view of marginal output. And the rural and urban structure is out of balance. That is to say, the marginal output of urban area is positive and the rural is negative, and the whole marginal contribution is negative.

\section{The low quality of employment and internal logic of 3D finance}

\subsection{The meaning of and criteria of $3 D$ finance}

Three-dimensional theory was first introduced by the famous Professor Bai Qin in 2013. Based on the concept, 3D integrated financial structure is composed of commercial finance, policy finance and cooperative financial, for deeper study in the view of philosophy, humanities, history and comprehensive view of economic and social research, combined action on the people's livelihood and welfare, economic development and social harmony, constitute a country's socio-economic system, an important foundation for financial system. We select three dimensional financial theories to explain the reasons for quality problems of employment, which is mainly reflected in the following aspects. The first finance plays an important role in promoting economic growth (Schumpeter's 1911; Oliver Goldsmith 1969). The second is commercial finance, which is from a more comprehensive perspective. Cooperative finance and financial policy interactions, together

\footnotetext{
${ }^{(1)}$ Readers who are familiar with mathematics would know that, when we get the natural logarithm of each term of the equation, and take the derivative of $t$, we can get the equation of $y$, which means the growth on the whole, $y$ $=2.382 *$ employment growth in urban areas-2.649*employment growth in rural areas $\left(g_{y}=2.382 * g_{c}-2.649 * g_{r}\right)$.Then, when the urban and rural employment grows at the rate of $1 \%$, the value of $y$ is -0.267 , Where $[\mathrm{LN}(\mathrm{X})]=\mathrm{dx} / \mathrm{x}$, meaning the actual growth of $\mathrm{x}$, i.e. $\mathrm{g}_{\mathrm{x}}$.
} 
forming the overall system structure (Bai hengxian and Wenhao 2013). Thirdly, policy finance and commercial finance do not have special features, such as direct support and facilitating functions (Baiqinxian and Wangwei, 2013). Employment is one of the four goals of the economic activities of the Government, which are needed to promote public policy, in particular the financial and fiscal policy. Fourthly, the 18th congress submitted "implement the strategy of giving priority to employment and contribute to a better quality of employment" and eighteenth third Plenary Session of "promoting employment and improve the government responsibility system" clearly states that "speed up financial reforms, improve the efficiency of the real economy, financial services. Sound commercial finance, development finance, and policy finance, cooperative finance is the theme. Studied at a reasonable division of labor, complementary financial system background, including commercial finance, policy finance and co-finance are referred to herein three dimensions financial.

\subsection{Reasons for analysis the low quality of employment with 3D finance regression}

Based on the analysis above, this paper selects the balance of loan of different banks from 2000 to 2013 as the dependent variables. These banks include commerce banks, policy banks and rural credit operations. The data comes from Financial Statistics Yearbook of China. What's more, considering the influence on independent variables brought by the dissimilation and regression of policy financial institutions from the year of $2008^{2}$. This paper introduces the virtual variable (D) to represent the dissimilation of finance. In this way, the development of finance can be described rigorously and authentically, which is of great features. Then we get the preliminary model as follows.

$$
I_{t}=\alpha+\beta_{1} P_{t}+\beta_{2} R_{t}+\beta_{3} C_{t}+\beta_{4} D_{t}+\xi_{t} .
$$

Among them, when $t<2008$, then $D_{t}=0$; when $t \geq 2008$ then $D_{t}=1$.

In order to keep the stability of data, we use the software SPSS20.0 to calculate the natural logarithm of the data. After the assessment, we can get the results as follows.

$$
\begin{aligned}
\text { Irurul }_{\mathrm{t}}= & \mathrm{e}^{-8.930} * \mathrm{P}_{\mathrm{t}}^{0.940} * \mathrm{R}_{\mathrm{t}}^{0.592} * \mathrm{C}_{\mathrm{t}}^{-0.536} * \mathrm{D}_{\mathrm{t}}^{-0.102} \\
& (-29.824)(5.693)(4.967)(-2.566)(-3.122) .
\end{aligned}
$$

Among them, when $t<2008$ then $D_{t}=0$; when $t \geq 2008$ then $D_{t}=1$.

$\mathrm{R}^{2}=0.999$, Adjusted $\mathrm{R}^{2}=0.998, \mathrm{~F}=1382.133$, Among the 5 variables above, the constant term, the policy finance $(\mathrm{P})$ and the rural cooperative finance $(\mathrm{R})$ undergo the significance test at a rate of $1 \%$, while the commercial finance $(\mathrm{C})$ and virtual variables undergo the significance test at a rate of $5 \%$.

As for the $2^{\text {nd }}$ model, we get the natural logarithm of each term of the equation, and take the derivative of $t$. Then we get the equation as follows.

When $\mathrm{t}<2008$, then

$$
\mathrm{g}_{\mathrm{ir}}=0.940 * \mathrm{~g}_{\mathrm{p}}+0.592 * \mathrm{~g}_{\mathrm{r}}-0.536 * \mathrm{~g}_{\mathrm{c}}
$$

When $\mathrm{t} \geq 2008$, then

$$
\mathrm{g}_{\mathrm{ir}}=0.940 * \mathrm{~g}_{\mathrm{p}}+0.592 * \mathrm{~g}_{\mathrm{r}}-0.536 * \mathrm{~g}_{\mathrm{c}}-0.102 * \mathrm{~g} \text {. }
$$

From the results of model (4), model $(4)^{*}$ and model $(4)^{* *}$, we can see that in the view of 3D finance, it has a positive effect on the three dimensions, i.e. the policy finance, the rural cooperative finance has a positive effect on the residents` income growth, which means that with the increasing of policy finance and rural cooperative finance, the income of rural residents rising. In the view of actual quantitative share, every one percentage point rise in policy finance and rural cooperative finance could boost the income of residents by 0.94 and 0.592 percentage point. While the commercial finance has a negative effect, which means that the faster the growth rate of commercial

\footnotetext{
${ }^{2}$ This phenomenon is a landmark event in the development of commercial banks to implement the reform of the state in 2008 by the Policy Banks To Developing Bank. More effects on Chinese policy financial Alienation and Regression of our society, economy and finance, please see Wang Wei and Zhang Qian to make co-authored Alienation and Return of Chinese financial policy, China Financial Publishing House, November 2010.
} 
finance, the faster the income of residents decreased. In the view of actual quantitative share, every one percentage point rise in commercial finance mean income of rural residents decreased by 0.536 percentage point. In the meanwhile, differentiation of policy finance has a negative effect on the income of rural residents. In the view of regression, since 2008 with the differentiation of policy finance, every one percentage point rise in differentiation, the growth rate of resident income decreases by 0.102 percentage point. Some researchers have pointed out that the international experience has shown that there is a mutual relationship between economic stagnation and income distribution, which may lead to some income traps for the fast-growing countries. While the middle class in China may suffer economic slowdown, so more attention should be paid to income gap (Cai Fang, 2013) ${ }^{[7]}$.

\subsection{Preliminary conclusion of regression analysis: the functional differentiation}

It can be seen that, policy finance, rural cooperative finance and commercial finance have an opposite and differentiate effect on the rural employment. To be more specific, the policy finance and rural cooperative finance can help to improve the quality of employment. However, the low quality of employment in rural area is responsible for the low level on the whole in our country, so the improvement of rural employment is more vital for the country. In the meanwhile, it is obvious that the differentiation of policy finance have a negative effect on the improvement of rural employment. While at present, the commercial finance doesn 't play the positive role in enhancing the employment quality in rural areas. On the contrary, it hinders the improvement of the employment quality to a certain extent and also affect the improvement of the overall quality of employment.

\subsection{Robustness test of the model}

We introduce the economic growth (GDP) as the common variable to have a robustness test. The main reason for the choice is mainly for the following two explanations. One, according to Solow`s neoclassical model of economic growth, employment growth changes with the economic growth. And Practice tells us that economic growth help to improve the income of workers or the two are mutually reinforcing. Second, in the bulletin of Third Plenary Session of $18^{\text {th }}$ and the framework of the Thirteen-Five Planning, it is suggest that we, especially for the farmers, should enjoy the positive outcome in economic growth after the reform and opening policy, and getting more feelings of satisfaction. Based on above, this paper establishes the following model on the basis of model 4.

$$
\text { Irurul }_{t}=\alpha+\beta_{1} P_{t}+\beta_{2} R_{t}+\beta_{3} C_{t}+\beta_{4} D_{t}+\beta_{5} G_{D P}+\xi_{t} .
$$

Among them, when $t<2008$, then $D_{t}=0$; when $t \geq 2008$, then $D_{t}=1$

In order to keep the stability of data, we use the software SPSS20.0 to calculate the natural logarithm of the data. After the assessment, we can get the results as follows.

$$
\begin{gathered}
\text { Irurul }_{\mathrm{t}}=\mathrm{e}^{-8.835 *} \mathrm{P}_{\mathrm{t}}{ }^{0.960} * \mathrm{R}_{\mathrm{t}}{ }^{0.498} * \mathrm{C}_{\mathrm{t}}{ }^{-0.549} * \mathrm{D}_{\mathrm{t}}{ }^{-0.092} * \mathrm{GDP}_{\mathrm{t}}{ }^{0.065} \\
(-29.970)(6.049)(3.733)(-2.741)(-2.861)(1.353) .
\end{gathered}
$$

Among them, when $\mathrm{t}<2008$ then $\mathrm{D}_{\mathrm{t}}=0$; when $\mathrm{t} \geq 2008$ then $\mathrm{D}_{\mathrm{t}}=1$.

$\mathrm{R}^{2}=0.999$, Adjusted $\mathrm{R}^{2}=0.998, \mathrm{~F}=1208.168$. Among the six variables above, the constant term, the policy finance $(\mathrm{P})$ and the rural cooperative finance $(\mathrm{R})$ undergo the significance test at a rate of $1 \%$; while, commercial finance $(\mathrm{C})$ and virtual variable undergo the significant test at a rate of $5 \%$, the economic growth doesn `t undergo the significant test at a rate of $10 \%$ (the confidence level of the variable is less than $80 \%$ ). So the variable of economic growth (GDP) does not overturn the basic estimate results in model 4 (see Table 1 ), which means that the $4^{\text {th }}$ model undergo the robustness test and shows that 3D finance have a negative and differentiate effect on the high quality employment to some degree. 
Table 1.Comparison the two results of two models differ in economic growth (GDP).

\begin{tabular}{lllllll}
\hline & $\begin{array}{c}\text { Constant } \\
\text { term }\end{array}$ & $\begin{array}{c}\text { Policy } \\
\text { finance }\end{array}$ & $\begin{array}{c}\text { Rural } \\
\text { cooperative } \\
\text { finance }\end{array}$ & $\begin{array}{c}\text { Commercial } \\
\text { finance }\end{array}$ & $\begin{array}{c}\text { Financial } \\
\text { dissimilation }\end{array}$ & $\begin{array}{c}\text { Economic } \\
\text { growth }\end{array}$ \\
\hline Model 4 & $-8.930^{* * *}$ & $0.940^{* * *}$ & $0.592^{* * *}$ & $-0.536^{* *}$ & $-0.102^{* *}$ & - \\
Model 6 & $-8.835^{* * *}$ & $0.960^{* * *}$ & $0.498^{* * *}$ & $-0.549^{* *}$ & $-0.092^{* *}$ & 0.065 \\
Compare & consistent & consistent & consistent & consistent & consistent & \\
\hline
\end{tabular}

Note: $* * *$ means undergo the significant test at a rate of $1 \%,{ }^{* *}$ means undergo the significant test at a rate of $5 \%, *$ means undergo the significant test at a rate of $10 \%$.

\section{Conclusions and policy recommendations}

\subsection{Science knows the topic of surplus rural workers}

According to the research on the marginal product of working from high quality employment, the marginal output of rural employment is actually negative. Therefore, under the existing conditions, the way to improve the employment quality is to reduce the rural population employment, so as to realize the marginal output considering with the economic sense "two negatives make a positive". In reality, reducing rural employment population is to transfer the rural surplus manpower step by step. No matter how many ways there are to achieve the goal, the consequence is that a great number of rural populations leave their hometown to urban area. Rural employment fell more than 100 million in the past 20 years, reduced by one percent per year on average, a population of nearly 6 million rural labor moves from countryside to cities and towns every year. However, over the past 20 years, the marginal output of rural employment has been a negative output. The transferring of rural surplus labor did not change the long-term existed negative influence to the economic growth. Therefore, from the perspective of the marginal output, the quality of employment in rural areas has been relatively low (negative in fact). Further combined with the decrease of social service in rural area, in long term perspective, to increase the transfer of rural surplus labor and rural urbanization construction is the only way to reverse the bad employment condition in rural area. The future of the countryside is that, perhaps just as skin Katie Thomas said, the evolution in the future depends on the view to the inequality from the society, and the policy and the system to deal with such inequality.

\subsection{Build a unified function of 3D finance}

High quality employment with balance between marginal input and output is a must to achieve a sustainable development in economic, society and ecology. In order to realize high quality employment, our society should meet the fundamental requirement of employment. In the meanwhile, assessment indicator system is an urge to build a scientific employment framework. While as the centre of the society, the finance plays an important role in improving employment quality, promoting economic developing and society progressing. Cai Fang (2015) further study the agriculture industry, and draws a conclusion that if the influx of money doesn 't enlarge the scale of production, and then there will be a waste in the progress of production. Under the 3D finance framework, the capital resource should first come back to rural to improve the farmers` employment quality, playing the positive function of finance policy. In the end, the aim is to realize the commercial, the policy and the cooperation finance integrated. The steps are as follows. Firstly, functions of political finance such as induction, expansion and siphon should be fully developed. Government should gradually guide the commercial finance and cooperative finance to rural areas and provide adequate products and services to farmers in order to go back to the agricultural economy. Moreover, governments should increase the supply of rural public goods and public service, especially the financial resources, for example, ATM which allows depositing and withdrawing money should be provided in every village. Monthly training on economic and finance knowledge can be held to gradually broaden the knowledge of farmers. 


\section{Acknowledgements}

National Social Science Foundation funded project milestones (No: 14BJY032)

\section{References}

[1] Adam Smith. Wealth (Chinese version) [M], Guo Dali, Wang Yanan, Shanghai Joint Publishing, 2009: 53-57.

[2] Rudolf Hilferding. Financial Capital (Chinese version) [M], Fumin, Commercial Press, 2012:411-423.

[3] Kong Weiwei, Qin Xinwei. Case Study on the Yield Contribution Rate of Heilongjiang's Industrial Capital [J]. Academic Exchange, 2006(04):94-97.

[4] David Romer. Advanced Macroeconomics (Chinese version) [M], Wang Genbei, Press of Shanghai University of Finance and Economics, 2009:12-18.

[5] Dong Keyong. Public Policy of Employment [J]. Economic Theory and Business Management, 2005(04):14-15.

[6] Hamid Boustanifar. Finance and employment: evidence from U.S. banking refom [J]. Journal of Banking\& Finance, 2014(46):345-354.

[7] Bai Qinxian, Wang Wei. Overview of Policy Finance [M].China Financial Publishing House, 2013:31-37.

[8] Cai Fang, Wang Meiyan. China’s Income Gap and Its Risk of Falling into Middle-Income Trap [J].Journal of Renmin University of China, 2014(3):2-3. 